\title{
Taxonomic study of the tribe Neohiraseini Hennemann \& Conle, 2008 (Phasmida: Phasmatidae: Lonchodinae) in continental China
}

\author{
George Wai-Chun Ho
}

Ho, G. W. C. 2012: Taxonomic study of the tribe Neohiraseini Hennemann \& Conle, 2008 (Phasmida: Phasmatidae: Lonchodinae) in continental China. Entomol. Fennica 23: 215-226.

Three genera and six species of the tribe Neohiraseini Hennemann \& Conle from continental China are recognized and discussed. Key to the genera and species of the tribe is provided. A new genus and species, Cheniphasma serrifemoralis gen. n., sp. n., from Guangdong are described. The female of Neohirasea guangdongensis Chen \& $\mathrm{He}$ is described for the first time.

G. W. C. Ho, Hong Kong Entomological Society, P. O. Box No.73749, Kowloon Central Post Office, Hong Kong; E-mail: georgehwc@hotmail.com

Received 18 December 2011, accepted 9 February 2012

\section{Introduction}

Neohiraseini Hennemann and Conle, 2008 is a recently established tribe which contains five genera and is principally restricted to Indo-China area (Hennemann \& Conle 2008: 78). In China, the tribe is composed of four different genera, Andropromachus Carl, 1913 (= Spiniphasma Chen \& He, 2000), Neohirasea Rehn, 1904 (= Paracentema Redtenbacher, 1908), Pseudocentema Chen, He and Li, 2002 and Qiongphasma Chen, He and Li, 2002 (Hennemann et al. 2008a). In the monograph of Chen and $\mathrm{He}$ (2008), Andropromachus, Pseudocentema and Qiongphasma are placed in Necrosciinae [Family: Diapheromeridae Kirby, 1904]. In the present study, the systematics largely follows Hennemann and Conle (2008). In China, the tribe is restricted to the southern and eastern regions (Hainan, Guangdong, Guangxi, Jiangxi, Hunan, Zhejiang, and Fujian Provinces).

Recent collecting trips to the well-preserved forests of the southern continental China revealed some interesting findings which contribute to the taxonomic knowledge of Neohiraseini. A new genus, which includes the new species, Cheniphasma serrifemoralis gen. n., sp. n., is described from Guangdong. It is characterized by the distinctly fin-like serrations of the dorso-anterior and dorso-posterior carinae of mesofemora and metafemora, distinctly paired tooth-liked lamellae on the middle of mesonotum in the female, strongly dilated and inwardly curved anal segment and unarmed ventro-anterior and ventro-posterior carinae of mesofemora and metafemora in the male.

Neohirasea is the most speciose genus of Neohiraseini. A total of four species is recognized from China by Hennemann et al. (2008a) and Chen and He (2008). The previously unknown female of $N$. guangdongensis Chen and He, 2008, is firstly described in this study. The occurrence of $N$. japonica (de Haan, 1842) in China is re-confirmed.

In this study, three genera and six species of Neohiraseini from continental China are recog- 
nized. Key to the genera and species of the tribe is provided. Two Hainan endemic genera, Pseudocentema Chen, $\mathrm{He}$ and Li, 2002, and Qiongphasma Chen, $\mathrm{He}$ and Li, 2002, are not discussed in the present study.

\section{Material and methods}

This study is based on the examination of type and non-type material in collections, literature review, the collection of specimens in various localities, as well as rearing of live specimens. The sequence of species account is in alphabetical order. The description of body armature is based on the acanthotaxy suggested by Rehn and Rehn (1939). Morphological terms follow Bragg (1997, 2001).

The specimens of the new genus and species examined in this study were collected directly by hand or net at night due to their nocturnal behavior. A hand torch was used to spot them on the plants. In order to preserve the colour of the specimen, specimens were cut between the second and seventh abdominal tergite for the removal of viscera by a forceps. The specimens were then stuffed with white cotton and dried.

The material mentioned in this paper is deposited in the following collections: Natural History Museum, London, England (BMNH); China Agricultural University, Beijing, China (CAU); Institute of Zoology, China Academy of Sciences, Beijing, China (IZCAS); Naturhistorisches Museum, Vienna, Austria (NHMW); Nationaal Natuurhistorisch Museum, Leiden, Netherlands (RMNH); Shanghai Entomological Museum, China Academy of Sciences, Shanghai, China (SEM); Shanghai Normal University, Shanghai, China (SNU); Centre for Insect Systematic, Universiti Kebangsan, Bangi, Malaysia (UKM); Zoologisches Museum der Universität, Hamburg, Germany (ZMUH); Zoological Reference Collection, Singapore (ZRC); Research Institute of Entomology, Zhongshan (Sun Yat-Sen) University, Guangzhou, Guangdong, China (ZSU), and private collections of following people: Francis Seow-Choen, Singapore (FSC); Ho, G. W. C., Hong Kong, China $(\mathrm{GH})$ and Paul D. Brock, Brockenhurst, England (PDB). Type material of the species described in this study is deposited in ZSU and GH.

\section{Systematics}

Family Phasmatidae Gray, 1835: 12.

Subfamily Lonchodinae Brunner von Wattenwyl, 1893: 80.

Neohiraseini Hennemann and Conle, 2008: 78. Type genus: Neohirasea Rehn, 1904: 84.

\subsection{Genera and species recorded in continental China}

- Genus Andropromachus Carl, 1913: 48.

- Andropromachus guangxiense (Chen \& He, 2000: 32).

- Genus Cheniphasma Ho gen. n.

- Cheniphasma serrifemoralis Ho sp. n.

- Genus Neohirasea Rehn, 1904: 84.

- Neohirasea guangdongensis Chen and He, 2008: 101, 392.

- Neohirasea hongkongensis Brock and SeowChoen, 2000: 123.

- Neohirasea japonica (de Haan, 1842: 135).

- Neohirasea stephanus (Redtenbacher, 1908: 477).

\subsection{Key to the genera and species of Neohiraseini Hennemann \& Conle, 2008 in continental China}

1. Occiput spinose, mesonotum distinctly swollen pre-medially

Andropromachus Carl, 1913, A. guangxiense (Chen \& He, 2000)

- Occiput smooth, mesonotum slender, moderately expanded posteriorly

2. Dorso-anterior and dorso-posterior carinae of mesofemora and metafemora protruded into four to six distinct fin-liked serrations; praeopercular organ on seventh sternum distinct, keel-like in female; ventro-anterior and ventro-posterior carinae of mesofemora and metafemora unarmed in male

Cheniphasma Ho gen. n.,

C. serrifemoralis Ho sp.n.

- Dorso-anterior and dorso-posterior carinae of mesofemora and metafemora smooth or slightly wave-like with flattened expansions, praeopercular organ absent or indistinct on 
the seventh sternum in female; ventro-anterior and ventro-posterior carinae of mesofemora and metafemora with two subapical spines in male 3. Neohirasea Rehn, 1904

3. Female

- Male

4. Lateral margins of mesonotum with long spine-like tubercles

N. stephanus (Redtenbacher, 1908)

- Lateral margins of mesonotum with small granules or short blunt tubercles

5. Small to medium size, body length $<55 \mathrm{~mm}$ N. guangdongensis Chen and He, 2008

- Medium to large size, body length $>55 \mathrm{~mm} 6$.

6. Mesonotum $>3 \times$ longer than pronotum, abdomen with distinct posterior tubercle, hind area of metapleurum with large pale maculation

$N$.japonica (de Haan, 1842)

- Mesonotum $<3 \times$ longer than pronotum, abdomen with indistinct posterior tubercle, hind area of metapleurum with small maculation

N. hongkongensis

Brock and Seow-Choen, 2000

7. Paired spines on anterior margin of pronotum apparently straight, not curved forward

N. hongkongensis

Brock and Seow-Choen, 2000

- Paired spines on anterior margin of pronotum distinctly curved, apices towards forward

N. guangdongensis Chen and He, 2008

\subsection{Genus Andropromachus Carl, 1913}

Type species. Andropromachus scutatus Carl, 1913: 49, by subsequent designation of Zompro (2002: 68).

= Spiniphasma Chen and He, 2000: 32. [Synonymised by Hennemann, 2007: 16]

Remarks. Four species are known from this Indo-Chinese genus. A review and redescription of Andropromachus and its synonym was provided by Hennemann (2007) and Hennemann et al. (2008b). Chen and $\mathrm{He}(2000,2008)$ originally placed Spiniphasma Chen \& He (a junior synonym to Andropromachus) in Necrosciinae [Diapheromeridae Kirby, 1904]. In this study, Spiniphasma Chen \& He, 2000 is regarded as a synonym of Andropromachus as in Hennemann (2007).

\subsubsection{Andropromachus guangxiense (Chen \&} $\mathrm{He}, 2000)$

Spiniphasma guangxiense, Chen and He, 2000: 32 (Fig. 7: 2).

Literature. Otte and Brock 2005: 46 [In catalogue of world species]; Hennemann 2007: 18 [Transferred to Andropromachus]; Hennemann et al. 2008a: 8 [In catalogue of Chinese species]; Hennemann et al. 2008b: 49 [Redescription]; Chen and He 2008: 202, figs.168a-d [First description of male].

Type material. China: Holotype 1, Mt. Damingshan, Wuming, Guangxi Autonomous Region, 23.V.1963, Yang Chikun (CAU); Paratype 19 , Hongtan, Huaping, Guangxi Autonomous Region, 12.VI.1963, Yang Chikun(CAU).

Further material. China: 1nymph $\odot, 400 \mathrm{~m}$, Luoxiang, Jinxiu, Guangxi Autonomous Region, 14.V.1999, Li Wenzhu (IZCAS); 1ठ, 1,000 m, Linhaishanzhuang, Jinxiu, Guangxi Autonomous Region, 2.VII.2000, Chen Jun (IZCAS); 1nymph $+, 900 \mathrm{~m}, 16 \mathrm{~km}$ Jinxiu, Guangxi Autonomous Region, 31.VII.2011, Zhu Jianqing (SNU).

Distribution. Restricted to Guangxi (Wuming, Huaping and Jinxiu), China.

Remarks. First description and illustration of male was provided by Chen and $\mathrm{He}$ (2008: 202).

\subsection{Genus Cheniphasma Ho gen. n. Figs. 1a-g \& 2a-b}

Type species. Cheniphasma serrifemoralis Ho sp. n., by present designation.

Diagnosis. Related to Neohirasea Rehn, 1904, Cheniphasma Ho is readily distinguished from it by serrated dorso-anterior and dorso-posterior carinae of mesofemora and metafemora, thoracic armature and distinctive praeopercular organ in female; and ventro-anterior and ventroposterior carinae of mesofemora and metafemora unarmed in male.

Description. Small to medium Neohiraseini. Dull colouration, brown to greenish brown or dark brown. Both sexes apterous. Body rugose and granulose, both sexes are covered with minute bristles throughout the body. Female robust, male smaller and slenderer than female. Head 
a

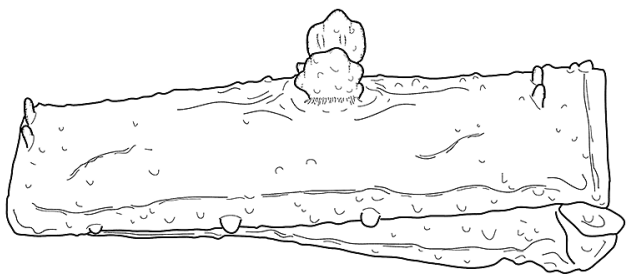

b
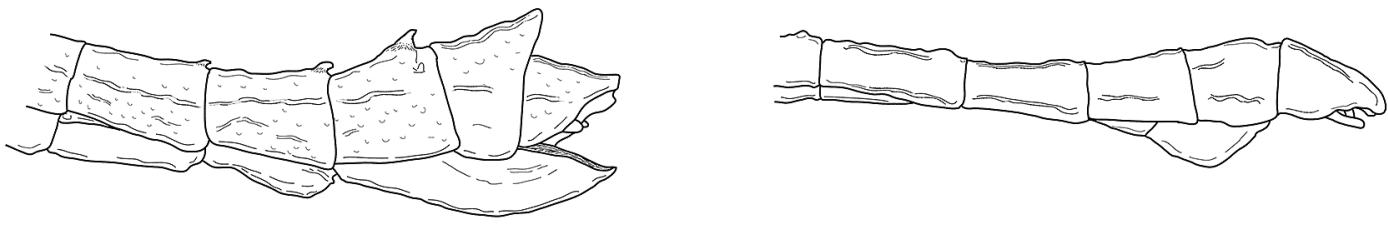

C

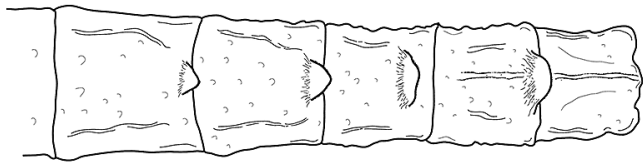

e
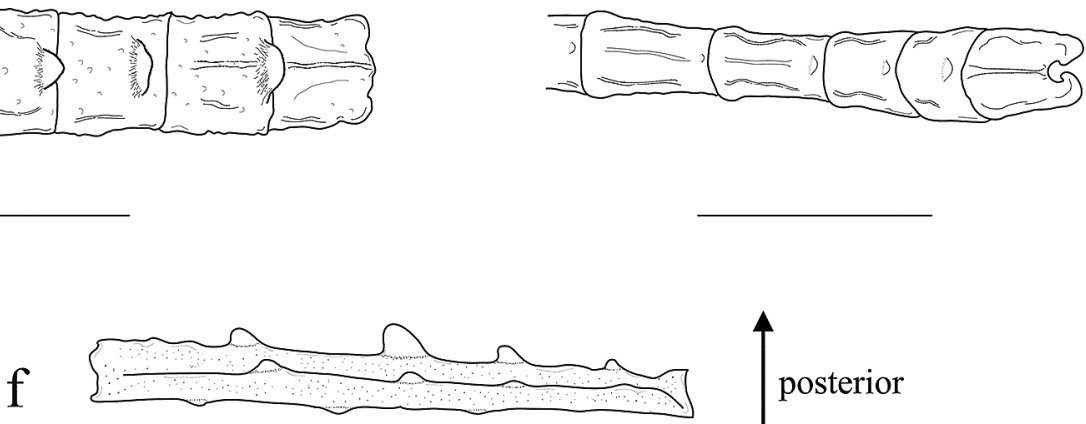

posterior

$\mathrm{g}$

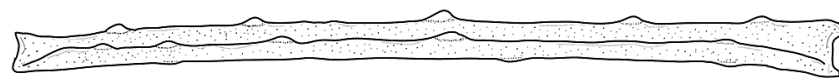
anterior

Fig. 1. Cheniphasma serrifemoralis Ho gen. n., sp. n. (scale bar $0.5 \mathrm{~mm}$ ). - a. Female holotype, mesothorax, lateral view. - b. Female holotype, apical half of abdomen, lateral view. $-c$. Female holotype, apical half of abdomen, dorsal view. - d. Male paratype, apical half of abdomen, lateral view. - e. Male paratype, apical half of abdomen, dorsal view. - f. Female holotype, mesofemur. - g. Female holotype, metafemur.

rounded, dorso-ventrally flattened. Vertex and occiput flat. Median and three lateral furrows distinct. Eyes oval, small and protruding. Antennae long, reaching to the apices of protarsi, sparsely covered with short bristles. Thorax tuberculate and granulose in female, spinose in male. Pronotum rectangular, antero-lateral angles truncate, with two anterior mesal pronotals. Mesonotum elongate, moderately expanded posteriorly, with anterior mesal mesonotals and posterior mesonotals being laterad of median carina in female or median line in male; middle of the carina strongly elevated with a pair of tooth-liked lamellae, apex denticulate or notched in female, only with a pair 


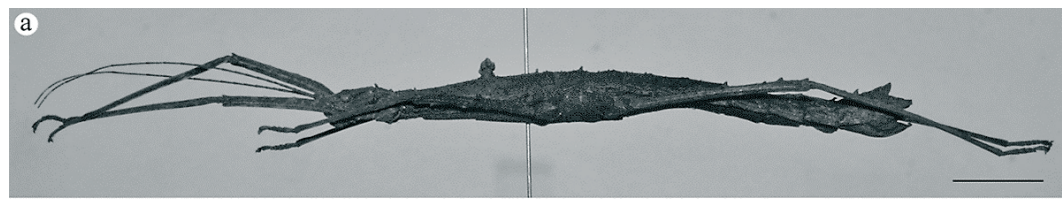

Fig. 2. Cheniphasma serrifemoralis Ho gen. n., sp. n. and $\mathrm{NeO}-$ hirasea guangdongensis Chen \& He (scale bar $1 \mathrm{~mm})$. - a. C. serrifemoralis, female holotype. - b. C. serrifemoralis, male paratype. c. N. guangdongensis, female.
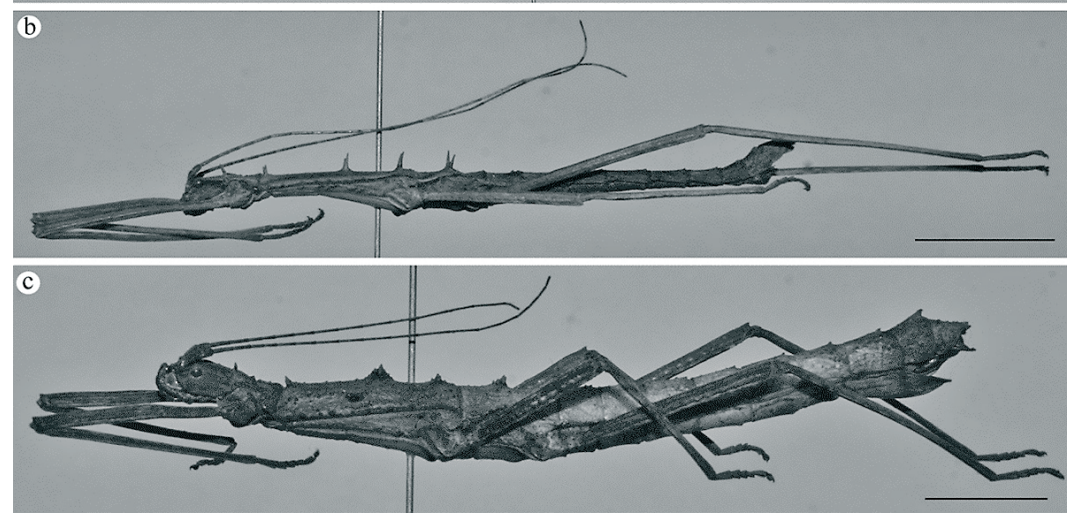

of spines on the middle of median line in male. Metanotum broader than long, with a pair of posterior mesal metanotals near hind margin. Abdomen with few minute granules and short wrinkles, narrowing posteriorly. Sixth to ninth tergites with a crest-liked structure medio-posteriorly, increased in size posteriorly in female. Second to eighth tergites with a minute granule medio-posteriorly in male. Female praeopercular organ distinct on seventh sternum, keel-like, slightly bifurcated posteriorly. Operculum of female scoopliked, reaching to the hind margin of anal segment. Anal segment of male spilt at half and dilated as two segments, apices thick, rounded and curved inward. Subgenital plate of male cupshaped, hind margin broad, reaching to the base of anal segment. Cerci of both sexes short and flattened, apices rounded. Legs thick-built, covered with long bristles. In female, dorso-anterior and dorso-posterior carinae of mesofemora and metafemora sparsely protruded into four to five fin-liked serrations. Ventro-anterior and ventroposterior carinae of mesofemora and metafemora indistinctly elevated with flattened serrations. Dorso-anterior and dorso-posterior carinae of mesotibiae and metatibiae distinctly with two to three wave-liked elevations. In male, all carinae of profemora and tibiae unarmed. Ventro-anterior and ventro-posterior carinae of mesofemora and metafemora slightly and indistinctly waved with elevations.
Distribution. Guangdong, China.

Etymology. This new genus is named in honour of Prof. Chen Shuchun (Beijing) for his huge contribution to the taxonomic study of Chinese Phasmida.

\subsubsection{Cheniphasma serrifemoralis Ho sp. n.}

Figs. 1a-g \& 2a-b

Type material. China: Holotype 19 , Heishiding, Fengkai, Guangdong Province, China, 25.VII. 2011, Ho Wai-Chun George (ZSU); Paratypes 1 ㅇ \& 1nymph우, Heishiding, Fengkai, Guangdong Province, 25.VII.2011, Ho Wai-Chun George (GH); Paratypes 2§1q, Heishiding, Fengkai, Guangdong Province, 13.VIII.2010, Ho Wai-Chun George, (ZSU, GH); Paratype 1nymph , , Heishiding, Fengkai, Guangdong Province, China, 17.VII.1999, Jiang Dan, En391023 (ZSU).

Description offemale. Medium size. Body robust, granulate and tuberculate. Adult from brown to greenish brown or dark brown. Colour of nymph similar to adult, but usually with pinkish white longitudinal median stripe running from occiput of head to seventh abdominal tergum.

Head. Rounded, dorso-ventrally flattened, slightly longer than wide, moderately expanded posteriorly, and not distinctly constricted at hind margin. Vertex flat, with two oval and carinate depressions between the base of antennae, size 
smaller than eyes. Hind margin of head with eight small swellings. Occiput flat, with several small granules, median and three lateral furrows distinct, anterior end of the median furrow reaching to the posterior margin of the depressions, posterior end of the median furrow reaching to the hind margin of head. Eyes oval, small, protruding, light brown. Antennae of 38-42 segments, brown as body, some segments darker, reaching to the apices of protarsi, about the total length of head and thorax combined together, sparsely covered with bristles; the first segment flattened at base, slightly parallel-sided, median carina distinct, longer than third segment; second segment shorter than the first segment and as long as third segment; terminal segment almost as long as third segment, apices pointed.

Thorax. With bristles, granulations and tubercles. Pronotum rectangular, shorter than head, slightly emarginated pre-medially and moderately expanded in posterior half, antero-lateral angles truncate; anterior margin with two anterior blunt mesal tubercles, apices towards forward; posterior margin rounded, with small inter-posterior and posterior granules; transverse sulcus and longitudinal sulcus crossing at the center of the pronotum, with pre-median and post-median granules being laterad of the longitudinal sulcus. Mesonotum elongate, rugose, granulose and with minute bristles, $3.5 \times$ longer than pronotum, moderately expanded posteriorly; tegmina reduced, scale-liked, placed postero-laterally; lateral margins with a row of granules, some larger, anterior margin with a pair of short mesal tubercles, near hind margin with a pair of short posterior tubercles being laterad of faint median carina and middle of the carina elevated with a pair of toothliked lamellae, apex denticulate or notched. Mesopleurum with one spine-like tubercle, one granule at posterior area and one to two small supra-coxals; lateral margins with five to six small granules. Metanotum broader than long, 1.5× longer than median segment, with an short oblique wrinkle, with a pair of posterior mesal tubercles near hind margin. Metapleurum with two supra-coxals, anterior one tubercle-liked, posterior one granule-liked, margin with three lateral granules. Mesosternum and metasternum with several small granules and minute bristles.

Abdomen. Narrowing posteriorly, granulose but less than on thorax, covered with minute bristles as thorax and distinctly rugose. Median segment fused with metanotum, granulose, $2 \times$ wider than long. Third to sixth tergites equal in length. Eighth tergum as long as tergum nine. Sixth to ninth tergites with a crest-liked structure medioposteriorly, increased in size posteriorly, apex obtuse. Praeopercular organ on seventh sternum distinct, keel-like, slightly bifurcated at posterior. Anal segment with median and lateral carinae, with two emarginations at hind margin, posterolateral angles rounded. Subgenital plate scoopliked, median carina distinct, reaching to the hind margin of anal segment. Cerci very short, flattened, apices pointed, not exceeding anal segment.

Legs. Thick, forelegs densely covered with long bristles, but less and shorter on midlegs and hindlegs. Profemora curved basally, nearly as long as mesonotum. Dorso-anterior and dorsoposterior carinae of profemora slightly waved with elevations, very indistinct. All ventral carinae of profemora unarmed. Dorso-anterior carinae of mesofemora and metafemora sparsely protruded into five small triangular serrations, equal in size. Dorso-posterior carinae of mesofemora and metafemora roughly protruded into four to five fin-liked serrations, median ones larger than others. The serrations on dorso-posterior carina of mesofemora generally larger than the serrations on dorso-anterior carina. Ventroanterior and ventro-posterior carinae indistinctly elevated with flattened serrations. Medio-ventral carina of mesofemora and metafemora unarmed. Protibiae unarmed. Dorso-anterior and dorsoposterior carinae of mesotibiae and metatibiae slightly with two to three wave-liked elevations, not distinct. All ventral carinae of mesotibiae and metatibiae unarmed.

Description of male. Medium size, slender body. Spinose and with few granulations. Dull colouration, generally brown to dark brown.

Head. Oval and longer than pronotum. Vertex flat, with carinate oval depressions between the base of antennae, size smaller than eyes. Eyes circular and small, brown. Hind margin with six indistinct swellings. Genae with broad blackish postocular band and with a creamy brown stripe above the band. Antennae filiform, reaching behind to fifth abdominal tergum; the first segment 
$2 \times$ longer than second segment; third segment longer than the first segment.

Thorax. Pronotum slightly shorter than head, parallel-sided, with a pair of anterior mesal spines at anterior margin, basally straight, apices weakly towards forward; transverse sulcus and longitudinal sulcus crossing at the center, with pre-median and post-median granules being laterad of the longitudinal sulcus. Mesonotum moderately expanded posteriorly, $3.7 \times$ longer than pronotum, with a row of pits along the lateral margins, anterior mesal spines placed at anterior margin, with a pair of short posterior tubercles being laterad of median line near hind margin and with a pair of spines placed at the middle of the median line; lateral carina distinct, posterior apex reaching to the two-third of the mesonotum. Mesopleurum with a long spine at hind area and a tubercle-liked supra-coxal spine. Metanotum with distinct carina and a pair of posterior mesal spines. Metapleurum with one spine at hind area. Mesosternum and metasternum with minute granules and bristles.

Abdomen. Slender, with few minute granules and short wrinkles. Parallel-sided from median segment to seventh tergites, expanded at eighth tergum. Third to sixth tergites equal in length. Median segment square. Second to eighth tergites with a minute granule medio-posteriorly. Eighth tergum slightly as long as the length of ninth tergum. Anal segment longer than ninth tergum, with distinct median and lateral carinae, spilt at middle of the segment, being dilated as two segments, apices thick and rounded, and apparently curved inward. Poculum cup-shaped, hind margin broad, reaching to the base of anal segment. Cerci flat, apices rounded, not projecting over anal segment.

Legs. Sparsely set with short bristles. Profemora curved basally, about the combined length of pronotum and mesonotum together, all carinae unarmed. Mesofemora as long as mesonotum. Ventro-anterior and ventro-posterior carinae of mesofemora and metafemora indistinctly waved with elevations. Dorsal carinae of mesofemora and metafemora unarmed. All tibiae unarmed.

Measurements. Lengths (mm): Holotype $q$, body length 61 , antennae 33 , head 4.5 , pronotum 4 , mesonotum 15 , metanotum 4 , median segment 2.5 , profemora 16 , mesofemora 12 , metafemora 18 , protibiae 16 , mesotibiae 13 , metatibiae 21 ;
Paratype 9 , body length 54, antennae 27, head 4, pronotum 3.5, mesonotum 12.5, metanotum 3.5, median segment 2, profemora 13.5 , mesofemora 11, metafemora 16, protibiae 14.5, mesotibiae 12, metatibiae 18; Paratype $\stackrel{\jmath}{\jmath}$, body length 43 , antennae $28-32$, head 3 , pronotum 2.5 , mesonotum 10-10.5, metanotum 3.5, median segment 1.51.8 , profemora 13 , mesofemora $10-10.5$, metafemora 14.5-15, protibiae 15-16.5, mesotibiae 12, metatibiae 19-19.5.

Distribution. Guangdong (Heishiding), China.

Remarks. The female measurement is only given to adult.

Etymology. "serrifemoralis" refers to the distinct serrations on female dorso-anterior and dorso-posterior carinae of mesofemora and metafemora.

\subsection{Genus Neohirasea Rehn, 1904}

Type species. Phasma (Acanthoderus) japonicum de Haan, 1842: 135, by original designation.

= Paracentema Redtenbacher, 1908: 477. [Synonymised by Zompro 2002: 68]

Remarks. Ten species are recognized from this Oriental genus. Four species are substantially known from continental China. No record of this genus is previously known from the Island of Hainan.

\subsubsection{Neohirasea guangdongensis Chen \& $\mathrm{He}$, 2008 Figs. 2c \& 3a-b}

Neohirasea guangdongensis, Chen and $\mathrm{He}$, 2008: 101, 392 (Figs.70a-c).

Type material. China: Holotype 1§̂, Heishiding, Fengkai, Guangdong Province, 8.X.1984, Zhu Feng (ZSU).

Further material. China: 1nymph $\widehat{\jmath}$, Heishiding, Fengkai, Guangdong Province, 16.VII. 1999, Meng Chen, En-391025 (ZSU); 19, Heishiding, Fengkai, Guangdong Province, 20.22.VII.2007, Jia Fenglong, En-391028 (ZSU); $1 \precsim 1$, , Heishiding, Fengkai, Guangdong Province, 13.VIII.2010, Ho, G. W. C. (GH); 6^4오, Heishiding, Fengkai, Guangdong Province, 25.27.VII.2011, Ho, G. W. C. (GH). 


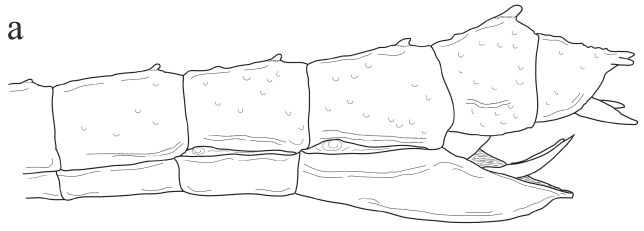

b

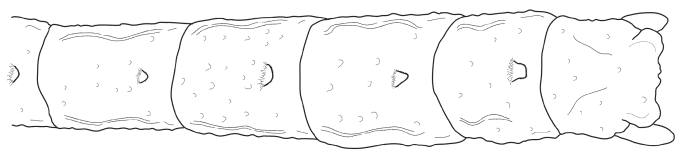

Fig. 3. Neohirasea guangdongensis Chen \& He (scale bar $0.5 \mathrm{~mm}$ ). - a. Female, apical half of abdomen, lateral view. $-b$. Female, apical half of abdomen, dorsal view.

Description of female. Small to medium size. Body robust and granulate. Generally brown to dark brown.

Head. Oval, slightly longer than wide, moderately tapering behind. Vertex flat, with two rounded elevations between the bases of antennae. Occiput gently convex, with median and two lateral furrows. Hind margin with six small swellings. Eyes small size, oval, brown. Antennae long, projecting behind protarsi, shorter than the length of abdomen; the first segment flattened at base, 1.5× longer than second segment and as long as third, median carina distinct; second segment cylindrical, as long as fourth segment.

Thorax. With spines, granulations and tubercles. Pronotum rectangular, shorter than head, with two small tubercle-liked anterior mesal spines at anterior margin, apices towards forward; transverse and longitudinal sulcus crossing at the middle, with two to four small granules being laterad of each sides of the longitudinal sulcus. Mesonotum widen towards the posterior, about $3 \times$ longer than pronotum, median carina distinct, gently elevated, with a bi-spined hump at the middle of the carina; pre-median area with a pair of long spines placed at the lateral carina, apex being directed laterally; anterior margin with a pair of mesal spines, longer than the anterior mesal pronotals and hind margin with a pair of posterior spines being laterad of median carina; lateral margins set with pits and four to eight small granules and spine-liked tubercles. Mesopleurum with a spine at posterior, lateral margin with four to seven small granules. Metanotum proportionally wider than long, 1.2-1.3× longer than median segment, with a pair of posterior mesal spines at hind area. Metapleurum with four to six small lateral granules and a spine at hind area, posterior margin with a medial spine. Mesosternum and metasternum with very few granules.

Abdomen. Narrowing posteriorly, with short wrinkles and small granules. Median segment trapezoid, fused with metanotum, $2 \times$ wider than long, with two small first paired posterior tubercles. Second tergum with two small first paired posterior tubercles. Seventh and eighth tergites with a depressed spine at hind. Ninth tergum elevated with a crest-liked structure posteriorly. Anal segment slightly as long as the length of ninth tergum, but shorter than eighth tergum, median carina indistinct, with two emarginations at hind margin. Subgenital plate scoop-shaped, with a lateral longitudinal keel in basal half, apex pointed, not exceeding the hind margin of anal segment. Cerci small, flattened, apices rounded, reaching to the postero-lateral angles of anal segment.

Legs. Long and thick, covered with small setae. Profemora almost as long as mesonotum. Mesofemora with a pale marking at the middle. Ventro-anterior and ventro-posterior carinae of mesofemora and metafemora with two small subapical serrations. All tibiae unarmed.

Measurements. Lengths (mm): Body length 52-57, antennae $27-28$, head 4-4.5, pronotum 3.5-4, mesonotum 11-12, metanotum 3.5, median segment 2.5 , profemora $12-13$, mesofemora 10, metafemora 15, protibiae 13.5-15, mesotibiae 11-12, metatibiae 17.5-18.

Distribution. Guangdong (Heishiding), China.

Remarks. This species is frequently encountered along the path at Heishiding.

\subsubsection{Neohirasea hongkongensis}

Brock \& Seow-Choen, 2000

Neohirasea hongkongensis, Brock and SeowChoen, 2000: 123 (Figs. 3 \& 4). 
Literature. Brock 2002: 56 [Note on the status in Hong Kong]; Brock 2003: 50 [Note on rearing culture]; Otte and Brock, 2005: 217 [In catalogue of world species]; Hennemann et al. 2008a: 17 [In catalogue of Chinese species]; Chen and $\mathrm{He}$ 2008: 101, figs. 71a-b.

Type material. China: Holotype 1ठ̄, Peel Rise, Victoria Peak, Hong Kong, 10.VII.1996, F. Seow-Choen $(\mathrm{BMNH})$; Paratypes $5 \hat{\jmath} 4$ 으, same data $(\mathrm{BMNH})$; Paratypes $3{ }^{\lambda} 3$ \% , same data (UKM); Paratypes $3 \hat{\jmath} 1$, same data (FSC); $\mathrm{Pa}-$ ratypes $1 \delta 1$, same data (PDB); Paratypes $6 \delta^{\lambda} 6$, same data (ZRC); Paratype $1 \hat{\jmath}$, Hong Kong, 1.I-31.XII.1911, F.W. Terry (BMNH); Paratypes $1 \overbrace{}^{\top}$ 2nymph, Hong Kong, 1.-31.V.1995, F. Seow-Choen (UKM).

Further material. China: 1q, Nei Lingding Island, Shenzhen, Guangdong, 15.X.1998, Chen Haitung, En-050668 (ZSU); 19, Fung Yuen, Hong Kong, 12.VIII.1996, Yip Shunyuan (SEM); 1§, Sam A Chung, Plover Cove, Hong Kong, 18.VIII.2003, Lo, P.Y.F. (GH); 1우 Tei Tong Tsai, Lantau Island, Hong Kong, 28.VIII.2003, Lo, P.Y.F. (GH); 19, Tai Tung Shan, Lantau Island, Hong Kong, 30.VI.2008, Ho, G. W. C. (GH); 1 , , Violet Hill, Hong Kong, China, 11.X.2008, Ho, G. W. C. (GH); 1 , Kowloon Peak, Hong Kong, 1.VI.2009, Ho, G. W. C. (GH); 1今, Tai Tung Shan, Lantau Island, Hong Kong, 20.VIII.2009, Ho, G. W. C. (GH); 1 , Aberdeen Reservoir, Hong Kong, VI.2010, Ho, G. W. C. (GH); 1§̂, Black's Link, Hong Kong, 19.VI.2010, Ho, G. W. C. (GH); 2 q, Ng Tung Chai, Hong Kong, 29.VI.2010, Ho, G. W. C. $(\mathrm{GH}) ; 1$, , Tai Po Kau, Hong Kong, 28.VIII.2010, Ho, G. W. C. (GH).

Distribution. Restricted to Hong Kong and the surrounding Guangdong area (Nei Lingding Island), China.

Remarks. Detailed descriptions of female and male were provided by Brock and Seow-Choen (2000: 123).

\subsubsection{Neohirasea japonica (de Haan, 1842)}

Phasma (Acanthoderus) japonicum, de Haan, 1842: 135 (Pl.12: 4).

$=$ Neohirasea lugens (Brunner won Wattenwyl, 1907: 244). [Synonymised by Hausleithner, 1992: 430]
Literature. Westwood 1859: 50; Kirby 1904: 325; Rehn 1904: 84; Brunner von Wattenwyl 1907: 245 [Placed in Menexenus Stål, 1875]; Shiraki 1911: 308 [As Acanthoderus japonicus de Haan, 1842]; Shiraki 1935: 59; Yasumatsu 1942: 7 [Illustrations of egg]; Chen and He 1987: 57 [Firstly reported from China]; Chen and $\mathrm{He}$ 1992: 44, fig.123; Hausleithner 1992: 430 [Note on data]; Bragg 1996: 111; Okada 1999: 29; Huang 2002: 86 [Illustrations of egg]; Otte and Brock 2005: 217 [In catalogue of world species]; $\mathrm{Xu}$ 2006: 61, fig.11 [Illustration of egg]; Hennemann et al. 2008: 18 [In catalogue of China species]; Chen and He 2008: 106, fig.72.

Type material. Japan: Syntype 19 , von Bürger, Decima, Japan (RMNH); Syntype 1옹 Japan, von Siebold (RMNH).

Further material. Japan: 2q, Kibune, 23.IX.1931, K. Eki (IZCAS); 1, Shimizu, Kyoto, 3.XI.1931, K. Eki (IZCAS); 19, Korama? (Japan?), 25.XI.1932, S. Yie (IZCAS); China: $1+$, Ou Yuen (Wuyuan, Jiangxi), Juilleb 34 (1934?), Yu Tsehong (IZCAS); 1 9 , Dadongshan, Lianxian Country, Guangdong Province, 5.IX.1992, Chen Haiguang, En-391026 (ZSU); 3 ㅇ, West Tianmushan, Linan, Zhejiang Province, 15.-28.VIII.2003, Hu Jiayao \& Tang Liang (SNU); 19 , West Tianmushan, Zhejiang Province, 15.-28.VIII.2005, Zhao Meijun (SNU); 2 ㅇ, Nanling, Shaoguan, Guangdong Province, 21.VII.2008, Ho, G. W. C. (GH); 1nymph우, Nanling, Shaoguan, Guangdong Province, 12.VI.2010, Ho, G. W. C. (GH); 1 \&, 300 m, West Tianmushan, Linan, Zhejiang Province, 15.IX. 2010, He Zhuqing (SNU); 5, Jinggangshan, Jiangxi Province, 31.VII-4.VIII.2011, Ho, G. W. C. (GH).

Distribution. Guangdong (Dadongshan and Nanling), Jiangxi (Jinggangshan and Wuyuan), Zhejiang (West Tianmushan) and Hunan, China. Also in Taiwan (Northern part) and Japan [Type locality].

Remarks. Neohirasea japonica de Haan, 1842 was originally described from Japan [Type locality] and was recognized as a new distribution record to China in Chen and He (1987: 57). Twenty years later, in the monograph of Chen and He (2008), the occurrence of $N$. japonica was subsequently regarded as a misidentification and was replaced by Paracentema stephanus 
Redtenbacher, 1908. In fact, Paracentema Redtenbacher is a synonym of Neohirasea Rehn (Zompro 2002: 68). The combined Neohirasea stephanus (Redtenbacher) is originally described from Vietnam and is substantially recorded in Guangxi only (Bi \& Li 1991: 107) [See the remarks in Neohirasea stephanus]. The other localities mentioned in Chen and He (2008: 106) should refer to this species or/and $N$. guangdongensis Chen \& He or/and $N$. hongkongensis Brock \& Seow-Choen. The distribution of N. japonica in China is mainly restricted to southeastern provinces of China. The mountain range of Nanling at north Guangdong is the most southern distribution of this species. Although there is currently no substantial record of this species from Guangxi, it could occur in eastern part of the region. No male $N$. japonica has been recorded and this species is believed to reproduce by parthenogenesis.

\subsubsection{Neohirasea stephanus (Redtenbacher,} 1908)

Paracentema stephanus, Redtenbacher, 1908: 477.

Literature. Bi and Li 1991: 107, figs.1-3 [First record of China and first description of male]; Brock 1998: 60; Bi et al. 2001: 253 [Misidentification]; Otte and Brock 2005: 246 [In catalogue of world species]; Chen and He 2008: 106.

Type material. Vietnam: Lectotype 19 , ThanMoi, Juni-Juli, H.Fruhstorfer, no.914 (NHMW); Paralectotypes 2q, Than-Moi, H. Rolle, no.914 (NHMW).

Further material. China: 29, Baishou, Guangxi Autonomous Region, 30.VI-6.VII. 1952, unknown collector (IZCAS); 1 , Guilin, Guangxi Autonomous Region, 10.IX.1953, unknown collector (IZCAS); 1 , , Yanshan, Guilin, Guangxi Autonomous Region, 23.VI.1980, unknown collector (SEM); 1nymphㅇ, Yanshan, Guilin, Guangxi Autonomous Region, 2.VI. 1985, Li Tianshan (SEM); 2 , Yanshan, Guilin, Guangxi Autonomous Region, 20.-24.IX.1988, Li Tianshan (SEM); 19, Yanshan, Guilin, Guangxi Autonomous Region, 14.VII.1989, Li Tianshan (SEM); 2 , Yanshan, Guilin, Guangxi Autonomous Region, 6.-23.VI.1990, Li Tian- shan (SEM); 19, 400 m, Luoxiang, Jinxiu, Guangxi Autonomous Region, 15.V.1999, Xiao Hui (IZCAS).

Distribution. Confined to Guangxi (Baishou, Guilin and Jinxiu), China. Also Vietnam [Type locality].

Remarks. Bi and Li (1991) firstly reported the occurrence of Neohirasea stephanus in China and gave a brief description for the male. Unfortunately, the material of male examined by $\mathrm{Bi}$ and Li was not traced in SEM. Therefore, it is not sufficient to distinguish from $N$. hongkongensis Brock \& Seow-Choen and N. japonica de Haan based on the very brief description, and not included in the taxonomic key. The distribution of this species is restricted to Guangxi. In Chen and He (2008: 106), the localities (Hong Kong, Guangdong [Shenzhen and Guangzhou], Zhejiang and Hunan) of $N$. stephanus should refer to $N$. guangdongensis Chen \& He or/and $N$. hongkongensis or/and N. japonica.

Acknowledgements. The author would especially like to thank Prof. Pang Hong (Head of Research Institute of Entomology, Zhongshan University) for her kind support and loan of specimens and Dr. Zhang Binglan, Mr. Xie Weicai, and Miss Tong Bo (Research Institute of Entomology, Zhongshan University) for their kind assistance. The author wishes to thank Prof. Yang Xingke, Prof. Yao Jian, Prof. Liu Hong, Dr. Bai Ming, Dr. Ge Siqin, and Miss Hu Xiaoyan (Institute of Zoology, China Academy of Sciences), Prof. Cai Wanzhi, Prof. Yang Ding and Prof. Wang Xinli and Dr. Liu Xingyue (China Agricultural University), Prof. Liu Xianwei, Prof. Yin Haisheng, and Dr. Zhu Weibing (Shanghai Entomological Museum) and Dr. Tang Liang, and Dr. Hu Jiayao (Shanghai Normal University) for their assistance and access to the collection. The author is also grateful to the staffs of Heishiding Nature Reserve, Guangdong and Jinggangshan Nature Reserve, Jiangxi for their field assistance. The author also thanks two anonymous referees who contributed significantly to the improvement of the manuscript and Miss So Wai Yan for proof-reading of the draft. Last, but certainly not least, this study would not have been possible without the help of Mr. Paul Brock (Natural History Museum, London) and Dr. Francis Seow-Choen (Singapore) who share material and literature.

\section{References}

Bi, D. Y. \& Li, T. S. 1991: Description of a new species and a new record of Phasmatodea from Guangxi, China (Phasmatodea: Heteronemiidae). - Contributions of Shanghai Institute of Entomology 10: 106-108.

Bi, D. Y., Zhang, W. N. \& Lau, C. S. K. 2001: Study of the 
Walking Stick Insects (Phasmatodea) and the genus Sipyloidea from Hong Kong District of China. - Entomotaxonomia 23: 253-258.

Bragg, P. E. 1996: Type specimens of Phasmida in the Nationaal Natuurhistorisch Museum, Leiden (Insecta: Phasmida). - Zoologische Mededelingen, Leiden 70: 105-115.

Bragg, P. E. 1997: A glossary of terms used to describe phasmids. - Phasmid Studies 6: 24.

Bragg, P. E. 2001: Phasmids of Borneo. - Natural History Publications, Kota Kinabalu, Borneo. 772 pp.

Brock, P. D. 1998: Catalogue of type-specimens of Stickand Leaf-Insects in the Naturhistorisches Museum Wien (Insecta: Phasmida). — Kataloge der wissenschaftlichen Sammlungen des Naturhistorischen $\mathrm{Mu}-$ seums in Wien 13: 1-72.

Brock, P. D. 2002: Hong Kong insects. — Reptilian 6: 54 59.

Brock, P. D. 2003: Rearing and studying stick and leaf Insects. The Amateur Entomologist 22. - The Amateur Entomologists' Society, Orpington, Kent, England. 89 pp.

Brock, P. D. \& Seow-Choen, F. 2000: The Stick insects (Insecta: Phasmida) of Hong Kong. - Serangga 5: 113147.

Brunner von Wattenwyl, K. 1893: Révision du Système des Orthoptères et description des espèces rapportées par M. Leonardo Fea de Birmanie. - Annali del Museo Civico di Storia Naturale Giacomo Doria, Genova 13: $1-230$.

Brunner von Wattenwyl, K. 1907: Die Insektenfamilie der Phasmiden. II. Phasmidae Anareolatae (Clitumnini, Lonchodini, Bacunculini). - Verlag, Engelmann, Leipzig. 157 pp. [In Latin.]

Carl, J. 1913: Phasmides nouveaux ou peu connus du Muséum de Genéve. - Revue Suisse de Zoologie 21: 156.

Chen, S. C. \& He, Y. H. 1987: Neohirasea japonica, new record of China Phasmatodea. - Journal of Beijing Forestry University 9: 57. [In Chinese.]

Chen, S. C. \& He, Y. H. 1992: Phasmida. — In: Peng, J. W. \& Lui, Y. Q. (eds.), Icnography of Forest Insects in $\mathrm{Hu}-$ nan China: 42-49. Hunan Science and Technology Publishing House, Changsha. 1473 pp. [In Chinese.]

Chen, S. C. \& He, Y. H. 2000: Three new genera and two new species of Heteronemiidae (Phasmatodea) from south China. - In Zhang, Y. L. (ed.), Systematic and Faunistic Research on Chinese Insects - Proceedings of the 5th National Congress of Insect Taxonomy: 3135. China Agricultural Science Press, Beijing. 331 pp. [In Chinese.]

Chen, S. C. \& He, Y. H. 2008: Phasmatodea of China. China Forestry Publishing House, Beijing. 476 pp. [In Chinese]

Chen, S. C., He, Y. H. \& Li, Y. 2002: Phasmatodea. — In: Huang, F. S. (ed.), Forest insects of Hainan: 100-116. Science Press, China. 1064 pp. [In Chinese.]

Gray, G. R. 1835: Synopsis of the species of insects belonging to the family of Phasmidae. Longman, London. 48 pp. de Haan, W. 1842: Bijdragen to de kennis der Orthoptera. — In Temminck, C. J. (ed.), Verhandelingen over de Natuurlijke Geschiedenis der Nederlansche Overzeesche Bezittingen, Verhandelingen Zoologie Vol.2: 45248. Luchtmans and van der Hoek, Leiden. 203 pp. [In Dutch.]

Hausleithner, B. 1992: Eine neue Menexenus-Art aus NEIndien und Vorarbeiten zu einer Revision der Gattungen Menexenus und Neohirasea (Phasmatodea: Phasmatidae: Lonchodinae). — Entomologische Zeitschrift 102: 423-434.

Hennemann, F. H. 2007: Notes on the genera Andropromachus Carl, 1913 and Spinohirasea Zompro, 2001. - Phasmid Studies 15: 15-26.

Hennemann, F. H. \& Conle, O. V. 2008: Revision of Oriental Phasmatodea: The tribe Pharnaciini Günther, 1953, including the description of the world's longest insect, and a survey of the family Phasmatidae Gray, 1835 with keys to the subfamilies and tribes (Phasmatodea: "Anareolatae": Phasmatidae). — Zootaxa 1906: 1316.

Hennemann, F. H., Conle, O. V. \& Zhang, W. W. 2008a: Catalogue of the stick and leaf-insects (Phasmatodea) of China, with a faunistic analysis, review of recent ecological and biological studies and bibliography (Insecta: Orthoptera: Phasmatodea. — Zootaxa 1735: 176.

Hennemann, F. H., Conle, O. V., Zhang, W. W. \& Liu, Y. 2008b: Descriptions of a new genus and three new species of Phasmatodea from Southwest China (Insecta: Phasmatodea). - Zootaxa 1701: 40-62.

Huang, Y. S. F. 2002: Phasmids in Taiwan. - Big Trees, Taiwan. 142 pp. [In Chinese.]

Kirby, W. F. 1904: A Synonymic Catalogue of Orthoptera. 1. Orthoptera Euplexoptera, Cursoria et Gressoria. (Forficulidae, Hemimeridae, Blattidae, Mantidae, Phasmidae). - British Museum, London. 501 pp.

Okada, M. 1999: (All About Japanese Stick-Insects). Tonbo-Shuppan Publishing, Osaka. 56 pp. [In Japanese.]

Otte, D. \& Brock, P. D. 2005: Phasmida Species File-Catalog of stick and leaf insects of the world. - The Insect Diversity Association and the Academy of Natural Sciences, Philadelphia. 414 pp.

Redtenbacher, J. 1908: Die Insektenfamilie der Phasmiden. III. Phasmidae Anareolatae (Phibalosomini, Acrophyllini, Necrosciini). — Verlag, Engelmann, Leipzig. 248 pp. [In Latin.]

Rehn, J. A. G. 1904: Studies in the orthopterous family Phasmidae. - Proceedings of the Academy of Natural Science of Philadelphia 56: 38-107.

Rehn, J. A. G. \& Rehn, J. W. H. 1939: The Orthoptera of the Philippine Islands, Part I. - Phasmatidae; Obriminae. - Proceedings of the Academy of Natural Science of Philadelphia 90: 389-487.

Shiraki, T. 1911: Phasmiden und Mantiden Japans. - Annotationes Zoologicae Japonenses, Tokyo 7: 291-315. [In German.]

Shiraki, T. 1935: Orthoptera of the Japanese Empire (Part IV) Phasmidae. - Memoirs of the Faculty of Science 
and Agriculture, Taihoku Imperial University, Formosa $14: 23-88$.

Stål, C. 1875: Recensio orthopterorum 3. Revue critique des Orthoptères décrits par Linné, DeGeer et Thunberg. Öfversigt af Kongliga Vetenskaps-Akademiens Förhandlingar - 32: 1-105.

Westwood, J. O. 1859: Catalogue of the orthopterous insects in the collection of the British Museum. Part I. Phasmidae. - British Museum, London. 196 pp.

$\mathrm{Xu}$, J. 2006: A taxonomic study on the adults and eggs in four genera of Heteronemiidae in China (Order: Phasmatodea). - Beijing Forestry University, Beijing, 70 pp. Unpublished Master-thesis. [In Chinese.]

Yasumatsu, K. 1942: Eggs of stick insects. - Bulletin of Takarazuka Insectarium 18: 1-20. [In Japanese.]

Zompro, O. 2002: Spinohirasea crassithorax, n. gen. n. sp., eine neue Stabschrecke aus Vietnam (Phasmatodea: Phasmatidae: Lonchodinae: Menexenini). — Bonner Zoologische Beiträge 50: 67-72. [In German.] 